6. Cheng MP, Papenburg J, Desjardins M, et al. Diagnostic testing for severe acute respiratory syndrome-related coronavirus 2: Ann Intern Med 2020; 172:726-734.

7. Abdalhamid B, Bilder CR, McCutchen LE, Hinrichs SH, Koepsell SA, Iwen PC. Assessment of specimen pooling to conserve SARS CoV-2 testing resources. Am J Clin Pathol 2020;153:715-718.
8. Yelin I, Aharony N, Shaer Tamar E, et al. Evaluation of COVID-19 RT-qPCR test in multisample pools. Clin Infect Dis 2020:ciaa531.

9. Lohse S, Pfuhl T, Berkó-Göttel B, et al. Pooling of samples for testing for SARS-CoV-2 in asymptomatic people. Lancet Infect Dis 2020 Apr 28 [Epub ahead of print]. doi: 10.1016/S1473-3099(20)30362-5.

\title{
Configuring a hospital in the COVID-19 era by integrating crisis management logistics
}

\author{
Abdulrahman Alharthy $\mathrm{MD}^{1}$, Fahad Faqihi MD${ }^{1}$, Huda Mhawish $\mathrm{MSc}^{1}$, Abdullah Balhamar $\mathrm{MD}^{1}$, \\ Ziad A. Memish MD, FACP ${ }^{2}$ and Dimitrios Karakitsos MD, PhD $^{1}$ (D) \\ ${ }^{1}$ Critical Care Department, King Saud Medical City, Riyadh, Kingdom of Saudi Arabia and ${ }^{2}$ Research \& Innovation Centre, King Saud Medical City, Riyadh, \\ Kingdom of Saudi Arabia
}

To the Editor-The novel coronavirus SARS-CoV-2 disease (COVID-19) emerged in China and has spread throughout the world. ${ }^{1}$ The first case of COVID-19 in Saudi Arabia was confirmed on March 2, 2020, and presently almost 200,000 people have been infected here. ${ }^{2}$ The Ministry of Health (MOH) has responded to the COVID-19 outbreak by designing clusters of governmental hospitals to accommodate the increased flow of patients. Although our bed-occupancy rates never exceeded $80 \%$ until 2019, the situation has changed dramatically since March 2020, when the intensive care unit (ICU) occupancy rates reached $100 \%$ due to the pandemic. Hence, our hospital has been under pressure to upgrade our ICU services. We have used crisis management tactics in configuring our medical city (Table 1). First, we created a multidisciplinary crisis management team (CMT) to supervise the operations, and we promptly applied a surge plan based on the available scientific evidence. Our CMT policies, ICU configuration strategy, staff and resource utilization, admission protocols, and therapeutic guidelines have been reviewed continually based on new international updates, emerging therapies, and the recommendations of our national health authorities. $^{2-5}$ By adjusting, and retrofitting existing ICUs, and acute wards. we have expanded the ICU bed capacity in a stepwise manner: phase 1, 180 beds; phase 2, 240 beds; phase 3, 300 beds). Our main challenge has been to install new structures (ie, gas access, power circuits, monitors, and HEPA purifiers) in the pop-up units. We could not maintain single-patient occupancy; thus, we isolated cohorts of COVID-19 patients in multiple-occupancy glass rooms. Nursing stations have been set up outside these rooms; new circuits have been installed for the transmission of data and alarms; and new procedure carts have been arranged for each new unit. The ICU-bed triage and

Author for correspondence: Dr Dimitrios Karakitsos, E-mail: karakitsosdimitrios@ gmail.com

Cite this article: Alharthy A, et al. (2021). Configuring a hospital in the COVID-19 era by integrating crisis management logistics. Infection Control \& Hospital Epidemiology, 42: 911-913, https://doi.org/10.1017/ice.2020.365 staff governance have been controlled by the CMT. Our CMT members have provided coverage 24 hours per day, 7 days per week to arrange the ICU admission flow and the transfer of patients to other hospitals based on the daily $\mathrm{MOH}$ plan. We have followed a tiered strategy in which we allocate experienced intensivists and nurses to supervise redeployed noncritical care physicians and nurses, and we also established back-up teams. The refinement of the respiratory and ICU care included changing the ventilator circuits and filters based on patient needs, avoiding nebulizers, creating specialized intubation and prone-positioning ventilation teams, and upgrading the oxygen supply system. The latter has been a major problem for our oxygen supply management team. Hence, we have promoted awake prone positioning and more oxygen-support therapies (ie, high-flow nasal cannula, and helmet continuous positive pressure ventilation) to avoid mechanical ventilation if possible. Interventional therapies (ie, extracorporeal membrane oxygenation and therapeutic plasma exchange) have been carefully screened by expert teams to optimize resource utilization. The ICU pharmacy operations have been linked to the $\mathrm{MOH}$ central stock and supervised by pharmacists of the CMT to facilitate the prompt delivery of medications. Infection control measures have been strictly implemented in all hospital areas by creating specific zones and protocols for donning and doffing personal protective equipment, providing sanitizer dispensers, applying strict room-disinfection protocols, and providing safe waste handling. ${ }^{6}$ Moreover, we have utilized novel transportation capsule isolation technology to minimize the risk of SARS-CoV-2 acquisition during inter- and intrahospital transportation. ${ }^{?}$

New hospital communication systems have been installed in the pop-up ICUs. The communication between frontline staff and the CMT is continuous. Because visitors were not allowed, family meetings were organized via web-based applications to reduce patient and family stress. Training and emotional staff support have been provided on a daily basis. We have utilized daily COVID-19 training sessions to provide additional emotional reassurance (ie, dual training and emotional support strategy). Moreover, 600 COVID-19 patients have been hospitalized in our ICU over the past 4 months. Our staff s nosocomial infection rate was $\sim 3 \%$ during the early stages of the pandemic, and it has decreased to $0.5 \%$ since May 2020. As the

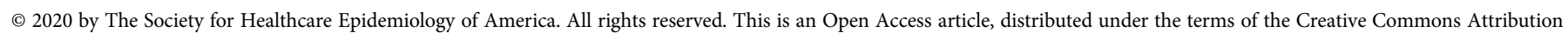

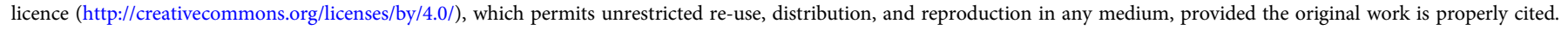


Table 1. Crisis Management Tactics in Configuring a Hospital by Upgrading its Intensive Care Unit Services in the COVID-19 Era

\begin{tabular}{|c|c|c|}
\hline Steps & Main challenges & Solutions \\
\hline $\begin{array}{l}\text { 1. Launched a multidisciplinary CMT to supervise } \\
\text { the operations }\end{array}$ & Team chemistry and communication & $\begin{array}{l}\text { Enhance communication and team bonds via daily } \\
\text { on site and virtual meetings. }\end{array}$ \\
\hline $\begin{array}{l}\text { 2. Constant review and adjustment of CMT policies, } \\
\text { ICU configuration strategy, staff/resource } \\
\text { utilization, admission protocols, and therapeutic } \\
\text { guidelines based on the international experience/ } \\
\text { recommendations, and local needs }\end{array}$ & Coordination of the flow of information & $\begin{array}{l}\text { Enhance debriefing and feedback provided by all } \\
\text { members of the team and facilitate central flow of } \\
\text { information to avoid confusion. }\end{array}$ \\
\hline $\begin{array}{l}\text { 3. Expansion of the ICU bed capacity in a stepwise } \\
\text { manner based on our set-up; adjusted and } \\
\text { retrofitted existing ICUs and acute wards. }\end{array}$ & $\begin{array}{l}\text { Infrastructural issues, resource dependent } \\
\text { process, inability to maintain single-patient } \\
\text { occupancy }\end{array}$ & $\begin{array}{l}\text { Boost new core structure development, optimize } \\
\text { resources via the } \mathrm{MOH} \text { command center, and } \\
\text { launch multiple-patient glass-door rooms to cohort } \\
\text { cases }\end{array}$ \\
\hline 4. ICU bed triage and staff governance & $\begin{array}{l}\text { Inability of the existing system to manage the } \\
\text { increased number of COVID-19 cases, staff } \\
\text { shortage }\end{array}$ & $\begin{array}{l}\text { Reroute admissions and transportation to other } \\
\text { COVID-19 centers via a dedicated nursing CMT } \\
\text { members ( } 24 / 7 \text { availability), tiered strategy for the } \\
\text { allocation of ICU (supervising), and non-ICU staff } \\
\text { (redeployed), and creation of backup teams to } \\
\text { ensure constant frontline rotation }\end{array}$ \\
\hline $\begin{array}{l}\text { 5. Refinement of the provided respiratory and ICU } \\
\text { care }\end{array}$ & $\begin{array}{l}\text { Oxygen supply issues, staff protection, shortage } \\
\text { of resources for advanced interventional } \\
\text { therapies }\end{array}$ & $\begin{array}{l}\text { Boosting the collaboration of technical support } \\
\text { teams, optimizing respiratory care practices, } \\
\text { reducing mechanical ventilation strategy by } \\
\text { boosting higher support oxygen therapies, creating } \\
\text { intubation/awake prone positioning teams, and } \\
\text { screening for clearance of interventional therapies } \\
\text { (ie, ECMO) by expert teams }\end{array}$ \\
\hline 6. ICU pharmacy optimization pathway & $\begin{array}{l}\text { Shortage and/or delivery delay of available } \\
\text { medications }\end{array}$ & $\begin{array}{l}\text { Enhance communication with central } \mathrm{MOH} \text { stocks, } \\
\text { and providers via dedicated CMT clinical } \\
\text { pharmacists }\end{array}$ \\
\hline 7. Strict application of infection control measures & $\begin{array}{l}\text { Staff awareness issues, space utilization for } \\
\text { donning and doffing of personal protective } \\
\text { equipment, shortage of resources, side-effects of } \\
\text { N95 continuous utilization }\end{array}$ & $\begin{array}{l}\text { Enhance staff training, application of specific } \\
\text { protocols for infection control and proper } \\
\text { utilization of personal protective equipment, daily } \\
\text { supervision of all applied measures, and staff } \\
\text { support by dedicated CMT members }\end{array}$ \\
\hline 8. The pivotal role of effective communication & $\begin{array}{l}\text { Integration of new communication hospital } \\
\text { systems, optimization of inter- and intrateam } \\
\text { communication }\end{array}$ & $\begin{array}{l}\text { Boosting the collaboration of technical support } \\
\text { teams, utilizing all available free cell phone and } \\
\text { web-based applications to ensure continuous } \\
\text { communication }\end{array}$ \\
\hline 9. Training and emotional staff support & $\begin{array}{l}\text { Unawareness of several COVID-19 related topics, } \\
\text { side-effects of N95 continuous utilization, and } \\
\text { fear of contamination, increased stress and } \\
\text { workload }\end{array}$ & $\begin{array}{l}\text { Daily dedicated training in all aspects of COVID-19 } \\
\text { care, providing on-site care for side effects of N95 } \\
\text { utilization, staff rotational schedule, utilizing } \\
\text { training sessions to increase the awareness about } \\
\text { infection control measures, and reducing } \\
\text { healthcare worker stress }\end{array}$ \\
\hline
\end{tabular}

Note. CMT, crisis management team; MOH, Ministry of Health; ICU, intensive care unit; ECMO, extracorporeal membrane oxygenation.

current wave of COVID-19 subsides, we are focusing on maintaining our costly infrastructure upgrades. These could ensure that a proper set-up would be available to meet future needs. ${ }^{3-5}$ Stores of equipment, medications, and technical gadgets remains under CMT supervision. Continuous medical education of our staff about COVID-19 by our $\mathrm{MOH}$ could facilitate the management of future outbreaks. Regardless of the limitations in any healthcare system, hospitals should be prepared for future pandemics.

Acknowledgments. We acknowledge all healthcare workers for their hard work and sacrifice in the fight against COVID-19 in Saudi Arabia.

Financial support. No financial support was provided relevant to this article.
Conflicts of interest. All authors report no conflicts of interest relevant to this article.

\section{References}

1. Guan WJ, Ni ZY, Hu Y, et al. Clinical characteristics of coronavirus disease 2019 in China. N Engl J Med 2020;382:1708-1720.

2. Coronavirus Diseases 19 (COVID-19) guidelines (revised version 1.7). Saudi Ministry of Health website. https://covid19.moh.gov.sa. Published May 25, 2020. Accessed July 22, 2020.

3. Griffin KM, Karas MG, Ivascu NS, Lief L. Hospital preparedness for COVID-19: a practical guide from a critical care perspective. Am J Respir Crit Care Med 2020;201:1337-1344. 
4. Xie J, Tong Z, Guan X, Du B, Qiu H, Slutsky AS. Critical care crisis and some recommendations during the COVID-19 epidemic in China. Intensive Care Med 2020;46:837-840.

5. Li L, Gong S, Yan J. COVID-19 in China: ten critical issues for intensive care medicine. Crit Care 2020;24:124.

6. Cheng V, Wong S-C, Chen J, et al. Escalating infection control response to the rapidly evolving epidemiology of the coronavirus disease 2019
(COVID-19) due to SARS-CoV-2 in Hong Kong. Infect Control Hosp Epidemiol 2020;41:493-498.

7. Almuabbadi B, Mhawish H, Marasigan B, et al. Novel transportation capsule technology could reduce the exposure risk to SARS-CoV-2 infection among health care workers: a feasibility study. Infect Control Hosp Epidemiol 2020; (in press Ms. No. 40738).

\title{
A model for shared clinical care in the COVID-19 crisis
}

\author{
Katrin Gillis $\mathrm{MSc}^{1}$ (10), Peter Van Bogaert MSc, $\mathrm{PhD}^{2}$, Hilde Servotte $\mathrm{MSc}^{3}$, Serge Lievens $\mathrm{MD}^{3}$, Henk Cuvelier MSc ${ }^{4}$, \\ Philip Nieberding $\mathrm{MD}^{5}$ and Veroniek Saegeman $\mathrm{PhD}^{6}$ \\ ${ }^{1}$ Department of Health Care, Odisee University College, Sint-Niklaas, Belgium, ${ }^{2}$ Antwerp University, Centre for Research and Innovation in Care, Antwerp, \\ Belgium, ${ }^{3} \mathrm{VzW}$ Samen-Ouder, Sint-Niklaas, Belgium, ${ }^{4} \mathrm{AZ}$ Nikolaas, Department of Nursing, Sint-Niklaas, Belgium, ${ }^{5} \mathrm{AZ}$ Nikolaas, Medical Department, Sint-Niklaas, \\ Belgium and ${ }^{6} \mathrm{AZ}$ Nikolaas, Department of Microbiology and Infection Control, Sint-Niklaas, Belgium
}

To the Editor-During the coronavirus disease 2019 (COVID-19) pandemic, it has become clear that the morbidity and mortality from COVID-19 are higher among elderly patients than in younger age groups in most Western countries. ${ }^{1,2}$ Moreover, elderly patients often live together in residential facilities, which increases their infection risk. In Belgium, very soon after the onset of the pandemic, a ban was put on family visits to residents of these facilities; this was one of the first measures before the start of a general lockdown. In Flanders, the Dutch-speaking part of Belgium, the government decided to have all residents and employees tested. Federal recommendations mentioned quarantine of severe acute respiratory coronavirus virus 2 (SARS$\mathrm{CoV}$-2)-positive residents on designated cohort units within residential care facilities. ${ }^{3}$

However, the Flemish Agency for Care approved the initiative of a group of residential care facilities to install a centralized special cohort unit for older adults with COVID-19. SARS-CoV-2infected residents from multiple residential facilities were transferred to this unit, as well as SARS-CoV-2-infected elderly adults who were discharged from hospitals but were too frail to return home. This special cohort unit was located in the Waasland region, and it provided shelter for residents from a group of 6 residential facilities that are part of a consortium (580 residents). A close collaboration was set up with an 810-bed regional hospital and coordinating physician of the primary care zone. The unit provided care for 10 residents, with the possibility to scale up with 10 additional places on standby. Four essential conditions had to be fulfilled before starting up such a unit: (1) the availability of infrastructure to enable barrier nursing; (2) the availability of a dedicated team with sufficient expertise in infection control and care for older adults; (3) the availability of sufficient supplies for care, treatment, and infection control; and (4) the possibility of fulfilling conditions 1-3 without influencing the regular residential care of the other units or the hospital. Due to the unprecedented and unseen impact of this crisis, the regional partners decided to apply the format of shared

Author for correspondence: Katrin Gillis, E-mail: katrin.gillis@odisee.be

Cite this article: Gillis K, et al. (2021). A model for shared clinical care in the COVID19 crisis. Infection Control \& Hospital Epidemiology, 42: 913-914, https://doi.org/10.1017/ ice. 2020.363 clinical care and provided the necessary infrastructure, materials, knowledge, and staffing (Fig. 1).

One of the residential facilities had an empty unit available with closed corridors (due to upcoming renovations). The unit had a separate entrance only accessible from the outside of the building that could be used by caregivers employed on the designated unit. Next, the needed protective and medical equipment (eg, IV therapy) were supplied by the regional hospital. Equipment for nursing care, maintenance, and meal distribution were provided by the other residential facilities of the consortium. Disposable materials were used as much as possible to limit the risk of iatrogenic infections, such as use of no-rinse disposable wash gloves during morning care and of disposable cutlery for meals.

The nursing team of the cohort unit was composed of 8 volunteer nurses and 2 nurse assistants (ie, 9 full-time equivalents, FTE). To ensure continuity on the other regular units in the residential facilities, vacancies created due to the absence of permanent staff were filled by nurses from the hospital. Seven of the nurses had bachelor's degrees, with an average work experience of 22 years, a level of experience and education above the average in regular units in Flemish residential facilities. ${ }^{4}$ The voluntary character and the level of education enabled nurses to work autonomously in this cohort unit during this crisis. Still, nurses had little experience with the principles of barrier nursing on cohort units, and they were therefore supported by hospital staff. In addition, the hospital also outsourced an infection prevention physician to share insights on infection prevention. Advice and procedures regarding personnel protection for healthcare workers were shared. Furthermore, a primary-care physician with specific expertise in infections in older adults was designated to the ward for the daily supervision of the medical follow-up of the residents on the unit.

Over 52 days, 15 residents were admitted to the special cohort unit. Among them, 13 were residents of the consortium and 2 individuals were admitted because they could not return home after discharge from the hospital. Unfortunately, 6 of these patients died. After 30 days, all members of the nursing team tested negative for COVID-19.

Due to the format of shared clinical care between the regional hospital, the consortium and the primary care zone, the conditions

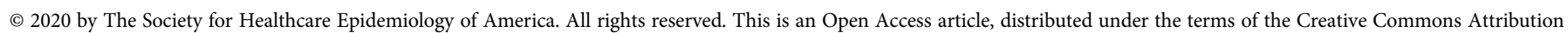

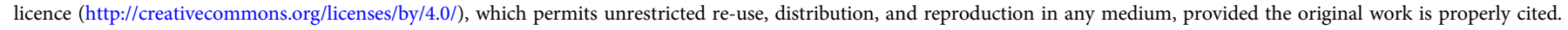

